\title{
New fabrication of CIGS crystals growth by a HVT method
}

\author{
Gang-Seok Lee, Hun-Soo Jeon, Ahreum Lee, Se-Gyo Jung, Seon-Min Bae, Dong-Wan Jo, Jin-Eun Ok, \\ Kyung-Hwa Kim, Min Yang, Sam-Nyeong Yi, Hyung Soo Ahn ${ }^{\dagger}$, Jong-Seong Bae* and Hong-Ju Ha** \\ Department of Applied Sciences, Korea Maritime University, Busan 606-791, Korea \\ *Busan Branch, Korea Basic Science Institute, Busan 609-735, Korea \\ **CS solution Co., Ltd., Busan 606-791, Koran
}

(Received May 28, 2010)

(Revised June 4, 2010)

(Accepted June 9, 2010)

\begin{abstract}
The $\mathrm{Cu}\left(\mathrm{In}_{1-\mathrm{x}} \mathrm{Ga}_{\mathrm{x}}\right) \mathrm{Se}_{2}$ is the absorber material for thin film solar cell with high absorption coefficient of $1 \times 10^{5}$ $\mathrm{cm}^{-1}$. In the case of CIGS, the movable energy band gap from $\mathrm{CuInSe}_{2}(1.00 \mathrm{eV})$ to $\mathrm{CuGaSe}_{2}(1.68 \mathrm{eV})$ can be acquired while controlling Ga contain ratio. Generally, the co-evaporator method have used for development and fabrication of the CIGS absorption layer. However, this method should need many steps and lengthy deposition time with high temperature. For these reasons, in this paper, a new growth method of CIGS layer was attempted to hydride vapor transport (HVT) method. The CIGS mixed-source material reacted for $\mathrm{HCl}$ gas in the source zone was deposited on the substrate after transporting to growth zone. c-plane $\mathrm{Al}_{2} \mathrm{O}_{3}$ and undoped $\mathrm{GaN}$ were used as substrates for growth. The characteristics of grown samples were measured from SEM and EDS.
\end{abstract}

Key words CuInGaSe, CIGS, Crystal, Growth, HVT, Mixed source, Chalcopyrite, Structure

\section{새로운 HVT 성장방법을 이용한 CIGS 결정성장}

이강석, 전헌수, 이아름, 정세교, 배선민, 조동완, 옥진은, 김경화, 양민, 이삼녕, 안형수 ${ }^{\dagger}$ 배종성*, 하홍주** 한국해양대학교 응용과학과, 부산, 606-791

*한국기초과학연구센터 부산분소, 부산, 609-735

**CSsol(주), 부산, 606-791

(2010년 5월 28일 접수)

(2010년 6월 4일 심사완료)

(2010년 6월 9일 게재확정)

요 약 높은 광흡수 계수를 $\left(1 \times 10^{5} \mathrm{~cm}^{-1}\right)$ 가지는 $\mathrm{CIGS}$ 는 Ga의 비율에 따라서 밴드갭을 조절할 수 있다는 장점을 지니고 있다. CIGS의 밴드갭은 $\mathrm{Ga}$ 의 비율에 따라 $\mathrm{CuInSe}_{2}(\mathrm{Eg}: 1.0 \mathrm{eV})$ 에서 $\mathrm{CuGaSe}_{2}(\mathrm{Eg}: 1.68 \mathrm{eV}$ )까지의 범위에 존재하며, 태양전지에 서 이상적인 fill factor 모양을 가지도록 Ga의 비율을 높게 조성한다. CIGS 흡수층을 제작하는 방법에는 co-evaporator 방식이 가장 널리 사용되며 연구되고 있다. 이에 본 연구에서는 수평 형태의 hydride vapor transport (HVT)법을 고안하여 CIGS 나노 구조 및 에피성장을 시도하였다. HVT법은 $\mathrm{N}_{2}$ 분위기에서 원료부의 CIGS 혼합물을 $\mathrm{HCl}$ 과 반응시켜 염화물 기체상태로 변환 후 growth zone까지 이동하여 성장을 하는 방식이다. 성장기판은 $\mathrm{c}-\mathrm{Al}_{2} \mathrm{O}_{3}$ 기판과 $\mathrm{u}-\mathrm{GaN}$ 을 사용하였다. 성장 후 field emission scanning electron microscopy(FE-SEM)과 energy dispersive spectrometer(EDS)를 이용하여 관찰하였다.

\section{1. 서 론}

$\mathrm{Cu}\left(\mathrm{In}_{1-\mathrm{x}} \mathrm{Ga}_{\mathrm{x}}\right) \mathrm{Se}_{2}$ 물질은 4원 화합물로 CIS계열의 I-IIVI족 화합물로서 chalcopyrite 구조를 이루고 있다. 성분 조성에 따른 밴드갭의 조절을 통해 태양전지 효율에 가

\footnotetext{
Corresponding author

Tel: +82-51-410-4781

Fax: +82-51-404-3986

E-mail: ahnhs@hhu.ac.kr
}

장 적합한 밴드갭인 $1.4 \mathrm{eV}$ 의 흡수층을 제작하기 용이하 며, 높은 광흡수 계수 $\left(1 \times 10^{5} \mathrm{~cm}^{-1}\right)$ 를 통해 보다 얇은 두께의 박막을 사용함으로써 태양전지 소자의 직렬저항 을 감소시켜 고효율 달성에 유리하다. 그리고 소자 제작 시 flexible한 특성 등 태양전지의 흡수층 재료로 적합한 장점을 가지고 있다. 또한 최근 신 재생에너지 산업이 각광을 받으며 성장함에 따라 태양전지 시장에서 주목 받고 있는 물질이다. 현재 상용화 되어있는 CIGS 박막 태양전지의 경우 co-evaporation 방법 등의 물리적 기상 
증착(physical vapor deposition: PVD) 방식을 주로 사용 하여 제작한다 $[1,2]$. 이 방식은 진공 챔버 내에 증발된 원 료들이 기체상태에서 무작위로 혼합되어 증착되는 방식이 기 때문에 일정한 물질 조성비의 CIGS 박막을 조절하기 어렵다는 문제점이 있으며, CIGS 결정질 형성에 있어서 비정질 박막의 소결공정에만 의존해야 한다는 단점이 존 재한다. 하지만 이러한 단점에도 불구하고 현재 최고 $19.9 \%$ 의 연구효율을 기록하고 있고, $16.4 \%$ 에 달하는 sub-module 연구효율과 독일의 Wurth Solavitt에 의해 $7,200 \mathrm{~cm}^{2}$ 의 대면적에서 최고 $13 \%$ 까지 확보한 상태로 고 효율 태양전지로써 장점들이 확인되고 있으며 $[3,4]$, 이러 한 상황에서 다결정의 CIGS 박막이 아닌 단결정의 CIGS 가 연구 개발된다면, 고효율 태양전지의 실현을 기대할 수 있다고 판단한다. 이에 본 논문에서는 새로운 hydride vapor transport(HVT)법을 고안하여 기존의 증착 후 소결 에 의존한 CIGS 결정질 형성이 아닌 기상법에 의한 성장 방식으로 새로운 형태의 CIGS 성장법을 제시하고자 한다.

\section{2. 실험방법}

본 논문에서는 $\mathrm{Cu}, \mathrm{In}, \mathrm{Ga}, \mathrm{Se}$ 네 가지 구성 재료를 $\mathrm{HCl}$ : DI water를 부피비 $1: 1$ 로 혼합한 용액에 원료 세 척을 실시 하였으며, 각 질량비 $3: 3: 1: 4$ 로 하나의 흑 연보트에 담아 $\mathrm{RF}$ furnace를 이용하여 $1090^{\circ} \mathrm{C}$ 의 고온 에서 약 1 시간 30 분 동안 합성하였다. 그 후 원료조성의 균일도를 향상시키기 위하여 막자사발로 분말형태의 CIGS 출발원료를 제작하였다. 원료 제작 후 일부분을 분리해서 FE-SEM과 EDS를 측정하여 결정상태와 대략 적인 조성비를 확인하였다. 기판은 동일한 육방정계 표 면을 갖는 c-sapphire 기판과 u-GaN/c-sapphire 기판을 $\mathrm{HF}$ 용액을 이용한 화학적 식각 과정으로 세척하여 준비 하였다. CIGS 성장을 위해 새롭게 시도한 HVT법은 $\mathrm{N}_{2}$ 분위기에서 원료부의 $\mathrm{CIGS}$ 혼합물을 $\mathrm{HCl}$ 과 반응시켜 염화물 기체상태로 변환 후 성장부까지 이동하여 성장을 하는 방식이다. 원료부의 온도는 $\mathrm{Se}$ 의 기화점에 가까운 $650^{\circ} \mathrm{C}$ 로 설정하였으며, 성장부는 $750^{\circ} \mathrm{C}$ 로 설정하였다. 성장시의 유량은 $\mathrm{HCl} 40 \mathrm{~cm}^{3} / \mathrm{min}$ 과 $\mathrm{N}_{2}$ 캐리어 가스 $200 \mathrm{~cm}^{3} / \mathrm{min}$ 를 함께 흘려 주었고, 성장은 성장존 온도 안정화 후 $\mathrm{HCl}$ 안정화 후 $\mathrm{HCl}$ 을 흘려주며 4시간 동안 성장 하였다. 성장된 기판은 그 후 FE-SEM과 $\mathrm{EDX}$ 를 통해 성장결과를 관찰하였다.

\section{3. 결과 및 고찰}

Fig. 1은 제작된 원료의 SEM 측정 및 EDS측정을 통
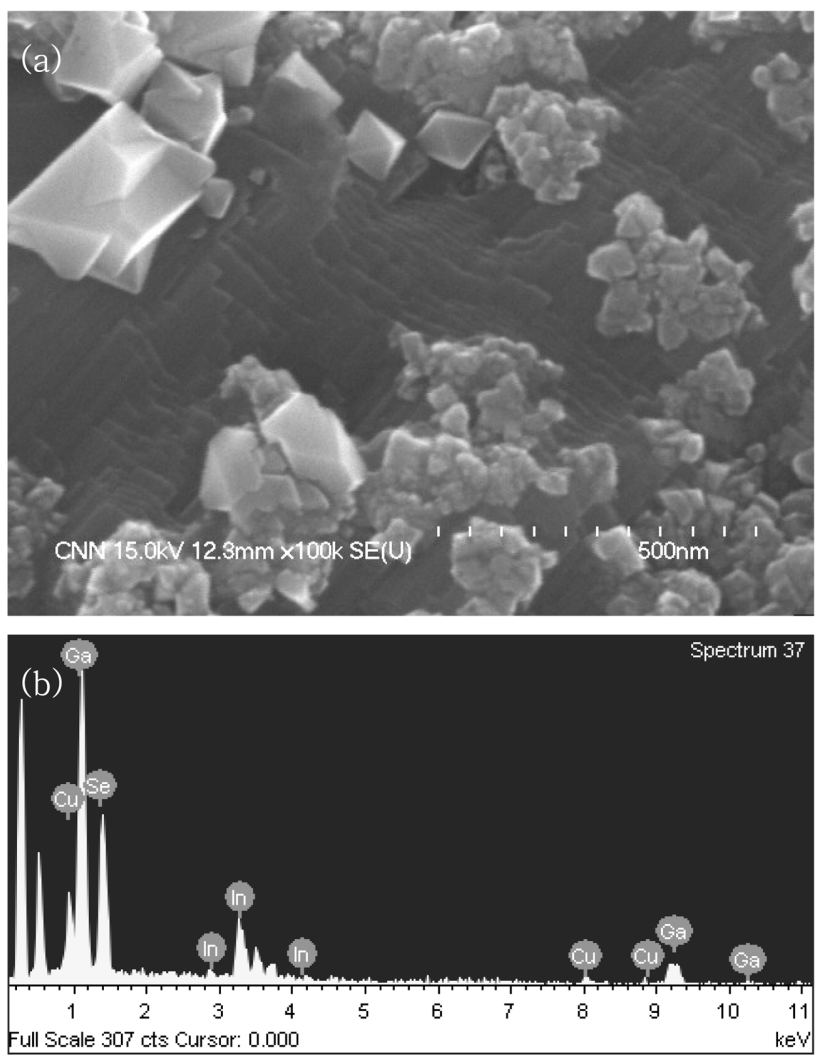

Fig. 1. (a) SEM image and (b) EDS mesurment result at the CIGS Source surface.

해 표면을 분석한 결과를 보여주고 있다.

Fig. 1(a)의 SEM 사진에서 원료 표면에 생긴 규칙적 인 형태의 절상무늬와 8 면체의 octahedral 구조의 결정 들이 관찰되었다. 이는 $\mathrm{Cu}, \mathrm{In}, \mathrm{Ga}, \mathrm{Se}$ 네 가지 구성 재 료들이 높은 온도에서 소성된 결과이며 Fig. 1의 (b)에 서 볼 수 있듯이 $\mathrm{EDS}$ 결과에 의해 $\mathrm{Ga}$ 과 $\mathrm{Se}$ 이 높게 조 성된 CIGS 혼합 원료임을 확인 할 수 있다.

\section{$\ln _{2} \mathrm{Se}_{3}$}

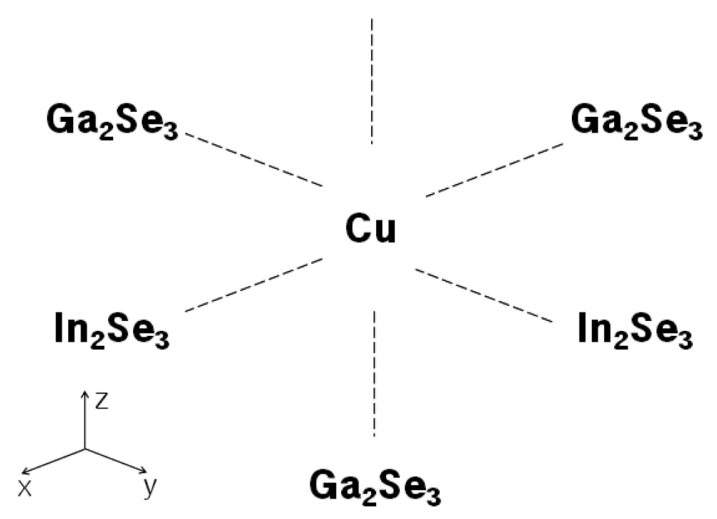

Fig. 2. transition metal and Ligands are has coordinate covalent bond to octahedral crystal on the CIGS source surface. 

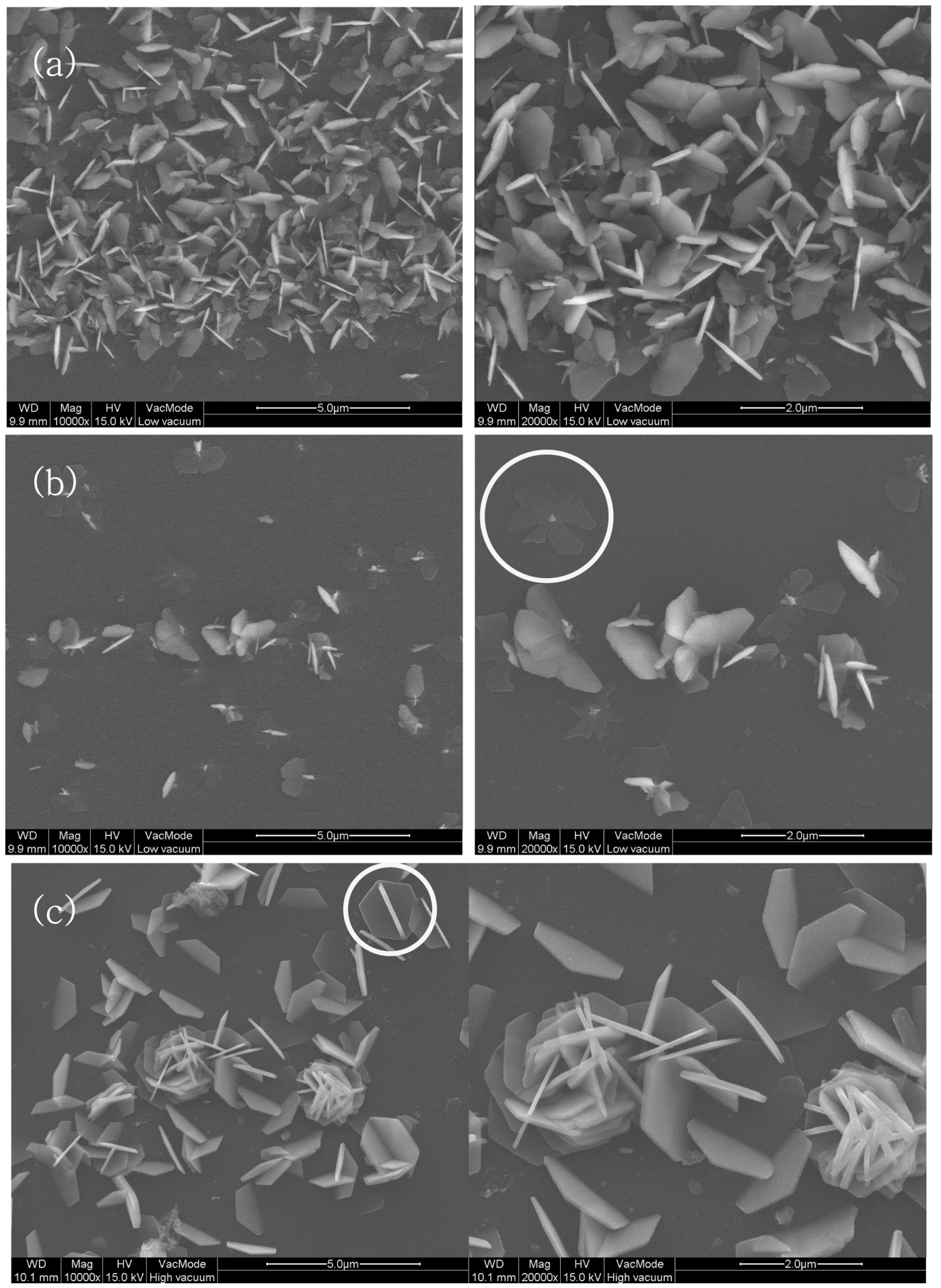

Fig. 3. $\mathrm{Cu}(\mathrm{InGa}) \mathrm{Se}_{2}$ grown on the (a), (b) c-sapphire substrate and (c) u-GaN substrate by HVT method.

Fig. 2는 CIGS 원료 표면에 형성된 octahedral 결정의 전이금속과 리간드들 간의 배위결합을 모식화한 것으로 표면 일부분에서 발견된 것과 같은 octahedral 형태의 결정의 경우 전이금속과 리간드와의 배위결합에 의해 형 성될 수 있으며, 그림에서와 같은 형태로 6 방향의 $\mathrm{In}_{2} \mathrm{Se}_{3}$ 및 $\mathrm{Ga}_{2} \mathrm{Se}_{3}$ (리간드)와 $\mathrm{Cu}$ (전이금속)간의 배위결합에 의해
형성된 것으로 예상한다.

Fig. 3는 위 원료를 사용하여 c-sapphire 기판 및 u-GaN/ c-sapphire 기판 위에 HVT법으로 성장한 샘플표면의 SEM 측정 결과이다. 기판의 종류에 따라 조금의 차이는 있지 만 hexagonal plate 형태의 구조들이 성장 되었음을 관 측 할 수 있다. Fig. 3(a)의 경우는 c-sapphire 기판위에 

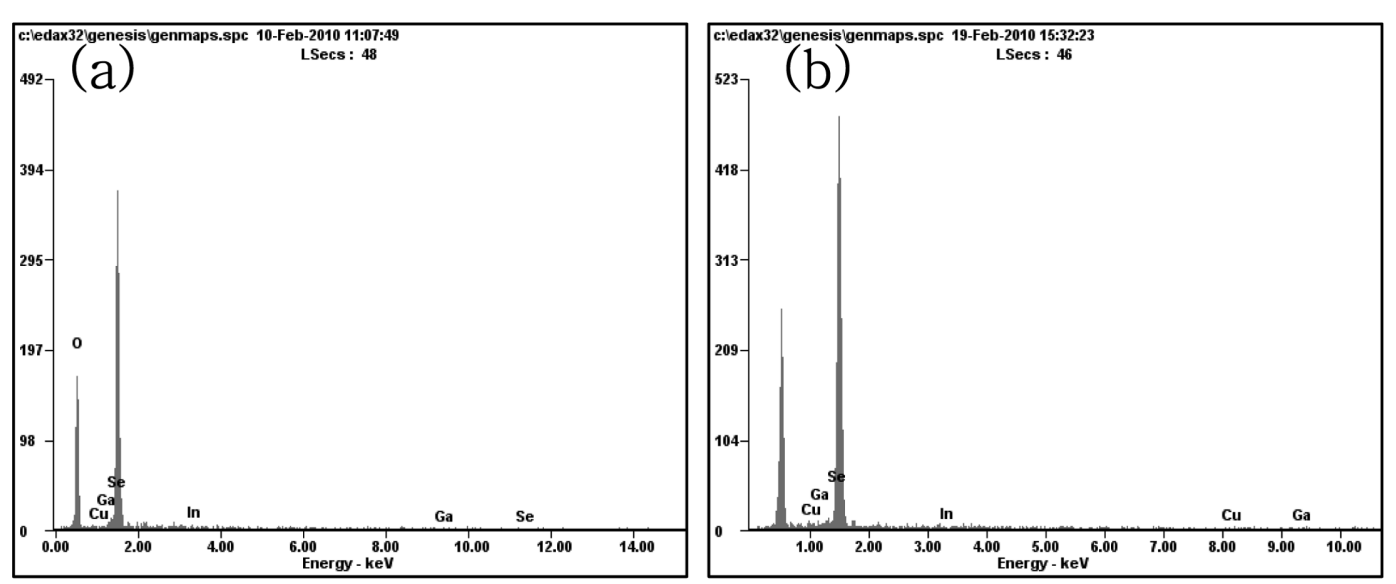

Fig. 4. EDS result of crystal grown on the (a) c-sapphire and (b) u-GaN substrates.
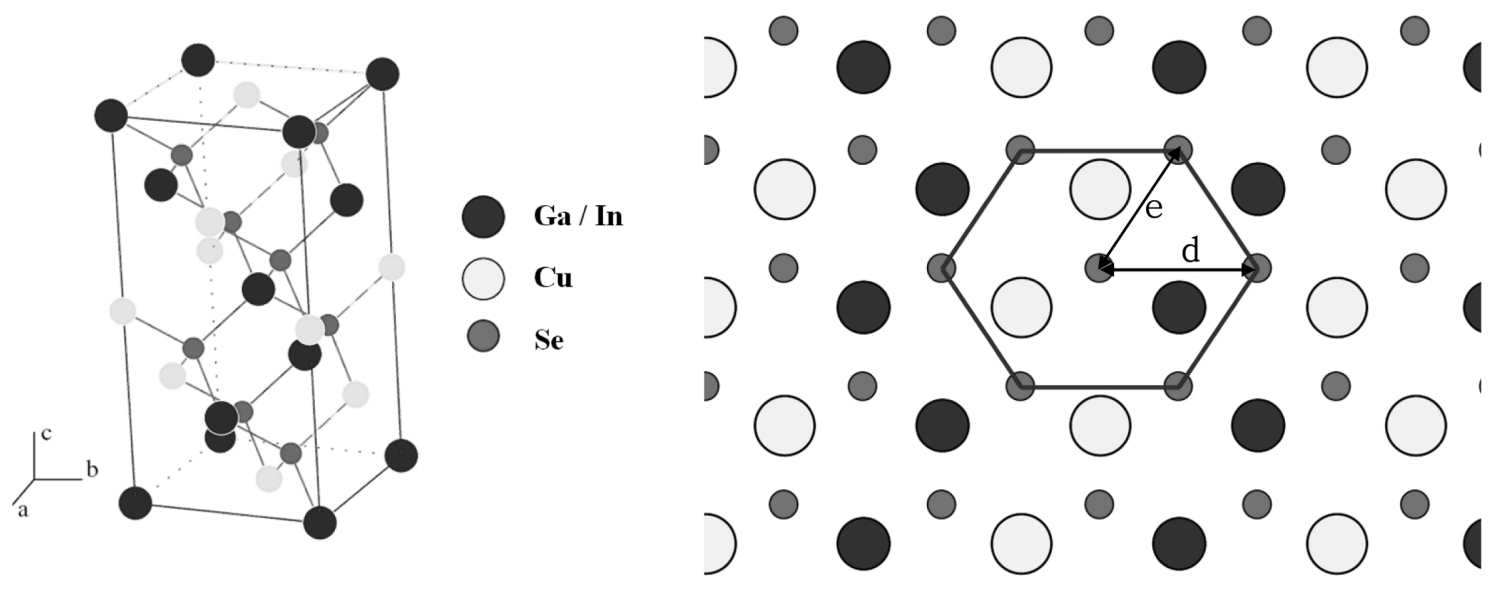

Fig. 5. (a) chalcopyrite structure and (b) (112) hexagonal plane of $\mathrm{CuInGaSe}_{2}$ crystal.

HVT법으로 성장 된 CIGS 결정들로서 hexagonal plate 의 폭은 수백 나노의 크기를 가지고 있음을 확인하였다. 성장된 hexagonal plate들과 기판표면 사이의 이면각의 크기는 기판의 종류와 무관함을 관찰할 수 있다. Fig. 3(b)의 경우는 (a)와 동일한 sample의 다른 위치에서 관 찰된 성장형태이며, Fig. 3(a)와 마찬가지로 hexagonal plate의 형상을 확인 할 수 있다. 특이하게 hexagonal plate의 형태가 완화되어 마치 나비 모양의 형태가 관측 되었다. 이는 CIGS의 원료들이 c-sapphire 기판위에 성 장되면서 초기 성장의 밀도가 높은 곳에서는 Fig. 3(a) 의 경우처럼 많은 hexagonal plate CIGS가 성장 되나 초기 성장의 밀도가 상대적으로 낮은 곳에서는 성장 조 성비의 불균일 때문에 완전한 형태의 hexagonal plate의 형태가 아닌 변형된 형태로 성장 되었다고 판단된다. 따 라서 HVT 법에서 가스의 laminar flow의 형성을 좀더 넓은 범위에서 균일하게 해 줄 필요가 있을 것으로 판단 된다. Fig. 3(c)의 경우는 $\mathrm{u}-\mathrm{GaN}$ 기판위에 HVT법으로 성장 된 CIGS 결정들로서 Fig. 3(a)와 같이 hexagonal plate의 모양을 볼 수 있으며 특히 hexagonal plate가 일
정한 곳에 모여 군집을 이루는 형태 즉, flower 형태를 확인 할 수 있다. 이는 $\mathrm{CIGS}$ 가 화합물 반도체이며 In과 $\mathrm{Ga}$ 이 혼합된 형태의 물질이므로 $\mathrm{GaN}$ 과 같은 기판을 사 용할 경우 초기성장을 촉진 시킬 수 있는 효과가 있음을 알 수 있다.

Fig. 4는 Fig 3의 각 샘플의 EDS 결과로서 기판강도 에 비에 상대적으로 미약하지만 $\mathrm{Cu}, \mathrm{In}, \mathrm{Ga}, \mathrm{Se}$ 이 모두 검출 되었다. 따라서 $\mathrm{HVT}$ 법에 의한 $\mathrm{CIGS}$ 의 성장이 가 능 함을 확인하였다.

Fig. 5는 $\mathrm{CuInGaSe}_{2}$ 의 (a) chalcopyrite 구조와 (b) hexagonal 형태의 (112)면을 도식화하였다. Fig. 3에서 관찰했을 때 전체적으로 기판 위에 hexagonal plate가 수직 방향으로 형성된 것을 알 수 있었다. 이러한 구조 는 Fig. 5 와 같이 기존의 $\mathrm{CuInSe}_{2}$ 계열의 결정들과 비 슷한 형태로 chalcopyrite 구조의 (001)면으로부터 [221] 방향 성장의 결과임을 예상할 수 있으며 SEM으로 관찰 되는 hexagonal면은 (112)면으로 판단된다[5,6]. 두 기 판 모두 [221]방향의 성장한 것으로 관찰되었지만 성장 된 hexagonal plate 형태가 다른 것을 확인하였다. Fig. 
3(a)의 경우 성장 분포 밀도가 높고 마치 나비날개 모양 처럼 보이는 반면, Fig. 3(c)의 경우 성장밀도는 낮지만 완전한 형태의 hexagonal plate 형태성장 된 것을 확인 하였고, 각각의 크기도 좀더 커진 것을 관찰하였다. Fig. 3(b)에서 보여진 c-sapphire 기판 일부분에 발견된 성장 형태는 $\mathrm{u}-\mathrm{GaN}$ 기판에서 보다 확연히 결정형태가 흐트러 진 것을 발견하였다. 이러한 현상을 앞에서 언급한 것과 같이 성장기판과의 격자부정합에 의한 것으로 판단하였다. $\mathrm{CIGS}$ 와 같은 4 원 화합물에서는 $\mathrm{In}$ 과 $\mathrm{Gs}$ 의 다른 원자반 경으로 인한 결합거리의 차이 때문에 격자상수가 $\mathrm{Ga}$ 의 혼합조성에 따라 $\mathrm{CuInSe}_{2}$ 와 $\mathrm{CuGaSe}_{2}$ 의 사이에서 형성 된다[7]. CIS, CGS 및 각 기판의 격자상수를 Table 1에 정리하였다[8-11]. $\mathrm{a}$ 축과 $\mathrm{c}$ 축의 격자상수 차이로는 $\mathrm{u}-$ $\mathrm{GaN}$ 기판보다 c-sapphire에서 더 격자부정합이 적을 것 으로 보이지만, $\mathrm{CIS}$ 계의 결정구조는 $\mathrm{Fig}$. 5 과 같은 chalcopyrite 구조이기 때문에 [221]방향 결정성장에 실질 적인 영향을 주는 (112)면간 거리는 기판에서의 (111)면 간 거리에 영향을 받는다. Table 1 에 $\mathrm{d}(111)$ 및 $\mathrm{d}(112)$ 를 면과 점의 거리 공식을 이용하여 계산하였다. 그 결 과, (112)면간 거리의 차이가 u-GaN기판 쪽이 더 작은 것으로 확인되었다. Fig. 2에서 hexagonal 구조로 전환 시 (0001)면의 Se원자간 거리를 각각 $\mathrm{e}$ 와 $\mathrm{d}$ 로 나타내었 으며, 각각의 거리계산 결과를 Table 2에 나타내었다. 그 결과 c-sapphire쪽이 많은 차이를 보여, 한쪽 방향으 로 치우친 육각형태를 나타낼 것으로 예상하였고, Fig. 3(b)의 결정 모양이 Fig. 3(c)의 결정모양보다 한쪽을 긴 육각형태의 모습을 보임으로써 예상과 일치함을 확인하 였다. 결과적으로 $\mathrm{CIGS}$ 결정성장에 있어 $\mathrm{u}-\mathrm{GaN}$ 기판이 결정성장에 더 유리함이 확인되었다.

이후 $\mathrm{u}-\mathrm{GaN}$ 기판을 이용하여 같은 조건하에 성장시간 만 8시간 이상으로 증가하여 다시 실험을 실시한 결과를

Table 1

Lattice constants and distance of plane to plane

\begin{tabular}{|c|c|c|c|c|c|}
\hline \multirow{2}{*}{ Compounds } & \multicolumn{3}{|c|}{ Lattice constant $(\AA)$} & \multirow{2}{*}{$\mathrm{d}(111)(\AA)$} & \multirow{2}{*}{$\mathrm{d}(112)(\AA)$} \\
\hline & $\mathrm{a}$ & $\mathrm{c}$ & $\mathrm{c} / 2$ & & \\
\hline $\mathrm{CuInSe}_{2}$ & 5.78 & 11.59 & 5.795 & - & 3.46 \\
\hline $\mathrm{CuGaSe}_{2}$ & 5.61 & 11.02 & 5.51 & - & 3.46 \\
\hline $\mathrm{GaN}$ & 3.19 & 5.18 & - & 3.39 & - \\
\hline $\mathrm{Al}_{2} \mathrm{O}_{3}$ & 4.75 & 12.98 & - & 3.23 & - \\
\hline
\end{tabular}

Table 2

Se bond length of on the hexagonal plane

\begin{tabular}{lll}
\hline Compounds & $\mathrm{d}(\AA)$ & $\mathrm{e}(\AA)$ \\
\hline $\mathrm{CuInSe}_{2}$ & 4.08 & 4.09 \\
$\mathrm{CuGaSe}_{2}$ & 3.97 & 3.93 \\
$\mathrm{GaN}$ & 2.26 & 3.04 \\
$\mathrm{Al}_{2} \mathrm{O}_{3}$ & 3.36 & 6.91 \\
\hline
\end{tabular}

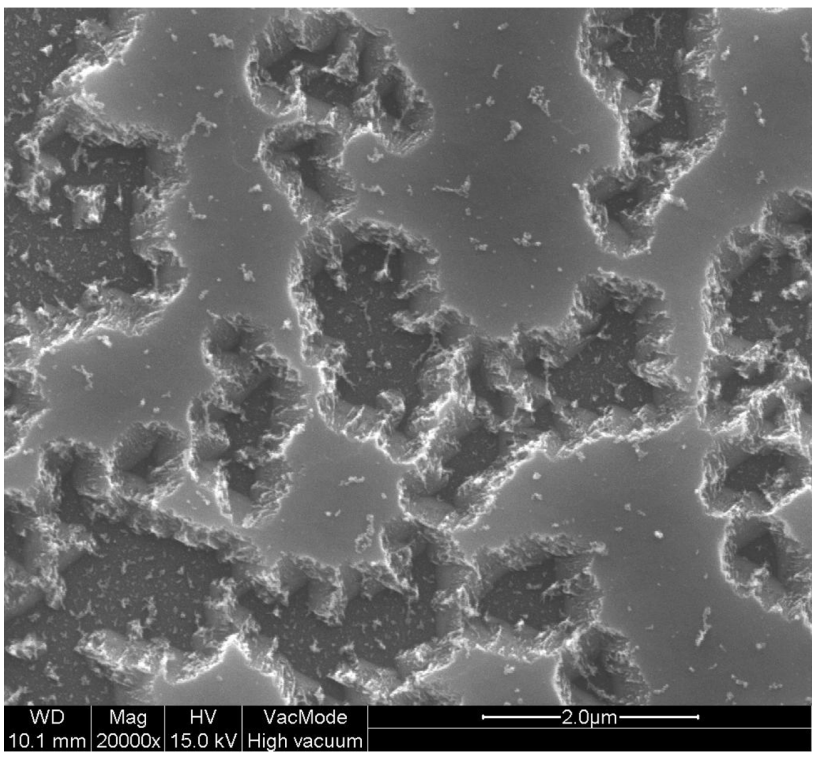

Fig. 6. SEM image of epitaxal growth on the u-GaN substrate.

Fig. 6에 나타내었다. HVT법으로 장시간 성장한 샘플에서 Fig. 6와 같은 평탄면을 확인 할 수 있으며 이는 CIGS 의 에피 박막의 성장의 가능성을 보여주는 결과라고 판 단된다.

\section{4. 결 론}

기존에 co-evaporation과 같은 PVD 기법과 차별화된 HVT법으로 c-sapphire 기판과 $\mathrm{u}-\mathrm{GaN}$ 기판 등 2종류의 기판에 결정성장을 시도하였다. 두 기판 모두 CIGS 결 정성장이 이루어졌으며, 두 기판의 격자상수에 따른 결 정성장 형태를 비교 분석한 결과, $\mathrm{u}-\mathrm{GaN}$ 기판에서 cSapphire 기판보다 CIGS 결정성장에 보다 유리함을 확 인 할 수 있었다. 이 후 보다 확실한 결정성장 상태를 확인하기 위해 $\mathrm{u}-\mathrm{GaN}$ 기판 위에서 성장시간을 8시간 이상 성장하였다. 그 결과 $\mathrm{SEM}$ 측정을 통하여 표면에 서의 2 차원 성장을 확인하였다. 이로써 우리의 새로운 HVT법을 이용하여 고효율의 박막태양전지의 흡수층으 로 사용 가능한 고품질 단결정 CIGS 박막의 성장의 가 능성이 기대된다.

\section{참 고 문 헌}

[ 1] X. Wu and J.C. Keane, "16.5\%-efficient CdS/CdTe polycrystalline thin-film solar cell", Proceedings of 17th European Photovoltaic Solar Energy Conference, Munich, 22-26 (October 2001) 995.

[2] R. Wuerz, A. Eicke and M. Frankenfeld, "CIGS thin- 
film solar cells on steel substrates", Thin Solid Films 517, Issue 7 (2009) 2415.

[ 3 ] I. Repins and M. Contreras, "Characterization of $19.9 \%$ efficienct CIGS absorbers", IEEE Photovoltaics Specialists Conference Record (2008) 33.

[ 4 ] J. Kessler, M. Bodegard and J. Hedstrom, "New world record $\mathrm{Cu}$ (In, $\mathrm{Ga}) \mathrm{Se} 2$ based mini-module: 16.6\%", Proceedings of 16th European Photovoltaic Solar Energy Conference, Glasgow (2000) 2057.

[ 5 ] F. Hergert, J. "A crystallographic description of experimentally identified formation reactions of $\mathrm{Cu}(\mathrm{In}, \mathrm{Ga}) \mathrm{Se}_{2}$ ", Solid State Chemistry 179, Issue 8 (2006) 2394.

[ 6 ] H. Tototzintle-Huitle and R. Baquero, "(l $\left.\begin{array}{lll}0 & 0 & 1\end{array}\right)$ Ideal-surface band structure for the series of Cu-based $\mathrm{ABC}_{2}$ chalcopyrites", J. Phys. Chem. Solids. 68, Issue 1 (2007) 1.

[ 7 ] J. Olejníček and C.A. Kamler, "A non-vacuum process for preparing nanocrystalline $\mathrm{CuIn}_{1-\mathrm{x}} \mathrm{Ga}_{\mathrm{x}} \mathrm{Se}_{2}$ materials involving an open-air solvothermal reaction", Sol. Energy Mater. 94, Issue 1 (2010) 8.
[ 8] L. Gladkikh and E. Rogacheva, "X-ray diffraction study of nonstoichiometry in $\mathrm{Cu}$ In Se2+d", Inorganic crystal structure database (ICSD), Web site: http://icsd.kisti.re.kr/ icsd/icsd_chemistry.jsp, Coll. Code: 91864.

[9] L. Mandel, R.D. Tomlinson and M.J. Hampshire, "Crystal structure of $\mathrm{Cu} \mathrm{Ga} \mathrm{Se}_{2}$ ", Inorganic crystal structure database (ICSD), Web site: http://icsd.kisti.re.kr/icsd/ icsd_chemistry.jsp, Coll. Code: 41809.

[10] X.-L. Chen, Y.-C. Lan and J.-K. Liang, "Structure and heat capacity of wurtzite Ga N from 113 to 1073 K", Inorganic crystal structure database (ICSD), Web site: http://icsd.kisti.re.kr/icsd/icsd_chemistry.jsp, Coll. Code: 87830.

[11] S. Pillet, M. Souhassou and Lecomte, "Recovering experimental and theoretical electron densities in corundum using the multipolar model: IUCr multipole refinement project", Inorganic crystal structure database (ICSD), Web site: http://icsd.kisti.re.kr/icsd/icsd_chemistry.jsp, Coll. Code: 92628. 